\title{
Transient mesenteric ischemia leads to remodeling of rat mesenteric resistance arteries
}

\section{Laura Caracuel ${ }^{1,2}$, Francesc Jiménez-Altayó ${ }^{1,2}$, Mónica Romo ${ }^{1}$, Ana Márquez-Martín ${ }^{1,2}$, Ana P. Dantas ${ }^{3}$ and Elisabet Vila ${ }^{1,2}$ *}

${ }^{1}$ Departament de Farmacologia, Terapèutica i Toxicología, Universitat Autònoma de Barcelona, Barcelona, Spain

2 Institut de Neurociencies, Universitat Autònoma de Barcelona, Barcelona, Spain

${ }^{3}$ Cardiologia Experimental, Institut Clínic del Tòrax, Institut d'Investigacions Biomèdiques August Pi i Sunyer, Barcelona, Spain

\section{Edited by:}

James B. Hoying, Cardiovascular

Innovation Institute, USA

Reviewed by:

Michael A. Hill, University of Missouri, USA

Stuart Egginton, University of Birmingham, UK

Jo G. R. De Mey, Maastricht

University, Netherlands

${ }^{*}$ Correspondence:

Elisabet Vila, Departament de Farmacologia, Terapèutica $i$

Toxicología, Universitat Autònoma de Barcelona, 08193 Bellaterra,

Barcelona, Spain.

e-mail: elisabet.vila@uab.es
Mesenteric ischemia/reperfusion (I/R) is associated with high rates of morbidity and mortality. We studied the effect of mesenteric I/R on structural and mechanical properties of rat mesenteric resistance artery (MRA) that, once disrupted, might impact the outcome of this devastating clinical condition. Superior mesenteric artery from Wistar-Kyoto rats was occluded $(90 \mathrm{~min})$ and reperfused $(24 \mathrm{~h})$. The effect of tezosentan, a dual endothelin (ET)receptor antagonist, was studied in ischemic $(\mathrm{IO})$ and sham-operated $(\mathrm{SO})$ animals. MRA structure and mechanics were assessed by pressure myography. Nuclei distribution, elastin content and organization, collagen I/III and ET-1 expression, ET-1 plasma levels, superoxide anion $\left(\mathrm{O}_{2}^{--}\right)$production, and mRNA levels of $\mathrm{NAD}(\mathrm{P}) \mathrm{H}$-oxidase subunits were measured. To assess ET-1 effects on $\mathrm{O}_{2}^{--}$production, MRA from non-operated rats were incubated in culture medium with ET-1. Mesenteric I/R increased MRA wall thickness $(P<0.05)$ and cross-sectional area $(P<0.05)$ but decreased wall stiffness $(P<0.05)$. Arterial remodeling was paralleled by enhancement of: (i) collagen $1 / I I I$ expression $(P<0.01)$, ET-1 expression $(P<0.05)$, and $\mathrm{O}_{2}^{--}$formation $(P<0.01)$ in the vessel wall; (ii) number of internal elastic lamina (IEL) fenestrae $(P<0.05)$; and (iii) plasma levels of ET-1 $(P<0.05)$. Moreover, ET-1 increased $\mathrm{O}_{2}^{-}(P<0.05)$ production in cultured MRA. Tezosentan prevented hypertrophic remodeling and collagen $\mathrm{I} / \mathrm{III}$ deposition, and enhanced $\mathrm{O}_{2}^{--}$production, but it did not affect the decreased wall stiffness after mesenteric I/R. These results indicate that $90 \mathrm{~min}$ occlusion/24 $\mathrm{h}$ reperfusion induces hypertrophic remodeling of MRA linked to ET1 -mediated increase of collagen and $\mathrm{O}_{2}^{-}$. Decreased stiffness may be associated with increased number of IEL fenestrae. The resulting MRA remodeling, initially adaptive, might become maladaptive contributing to the pathology and poor outcome of mesenteric $I / R$, and might be a valuable treatment target for mesenteric l/R.

Keywords: ischemia/reperfusion, structural and mechanical properties, oxidative stress, endothelin

\section{INTRODUCTION}

Interruption of blood flow to intestinal tissue caused by thrombi, embolisms, or secondary to other non-occlusive processes (Massberg and Messmer, 1998; Stefanutti et al., 2004) results in ischemic injury to the small intestine. While reperfusion of ischemic intestine is essential, it leads to a sequence of events known as mesenteric ischemia/reperfusion ( $\mathrm{I} / \mathrm{R})$ injury, which is a life-threatening clinical complication.

The status of arterial flow in the mesenteric vasculature is a successful diagnostic tool for identifying the presence and the causes of mesenteric I/R (Ridley and Green, 2001). However, little has changed in the last four decades with regard to overall mortality, which remains approximately $40 \%$, and medical management (i.e., anticoagulation or antiplatelet therapy) is essential for all survivors (Sise, 2010). Decreased intestinal contractile activity (Ballabeni et al., 2002), increased microvascular permeability and dysfunction of mucosal barrier (Carden and Granger, 2000) have been reported after mesenteric I/R. Furthermore, distant pathophysiological effects have also been observed, including remote organ injury (Carden and Granger, 2000) and rise in blood pressure (Khanna et al., 2001). However, mean arterial pressure returns to control values toward the end of ischemia and decreases during reperfusion (Hayward and Lefer, 1998; Khanna et al., 2001). These results illustrate the complexity of the cardiovascular response during mesenteric $\mathrm{I} / \mathrm{R}$ and highlights the need for further studies.

Alterations of resistance arteries reactivity (i.e., endothelial dysfunction, altered contractility) play an important role in the pathogenesis and progression of cardiovascular diseases (Vila and Salaices, 2005). Abnormal vascular remodeling is also a well recognized predictor and has a primary role in vascular pathologies (Intengan and Schiffrin, 2001; Briones et al., 2010). Vascular remodeling leading to structural changes is known to occur in response to diverse physiological and pathological stimuli, including mechanical forces, neurohumoral factors, and paracrine agents (Martinez-Lemus et al., 2009). For example, vasoactive substances 
like nitric oxide and endothelin-1 (ET-1) have been involved in vascular remodeling (Martens et al., 2002; Harris et al., 2005). In addition, reperfusion of blood to the tissues leads to the generation of oxygen free radicals (Gourdin et al., 2009) and the release of pro-inflammatory cytokines (Cuzzocrea et al., 2002), which have been largely associated with disturbance of vascular structure (Stenmark et al., 2006; Jiménez-Altayó et al., 2009). Structural and mechanical characteristics of resistance arteries are critically involved in the regulation of blood pressure and the regional distribution of blood flow (Martinez-Lemus et al., 2009; Van den Akker et al., 2010). Therefore, remodeling of resistance arteries can contribute to hemodynamic dysfunction (Martinez-Lemus et al., 2009).

Numerous studies have attempted to find an ideal therapy for mesenteric I/R, although, the mechanisms of ischemia and posterior reperfusion injury have not been completely clarified. In the present study we aimed to evaluate whether transient superior mesenteric artery occlusion and reperfusion could influence the structural and mechanical properties of mesenteric resistance arteries (MRA) that, once disrupted, might make an important contribution to the development of cardiovascular complications.

\section{MATERIALS AND METHODS}

The investigation conforms to the Guide for the Care and Use of Laboratory Animals published by the US National Institutes of Health (NIH Publication No. 85-23, revised 1996). Approval for the work was granted by the Ethics Committee at the "Universitat Autònoma de Barcelona." Thirteen- to fourteen- week-old male Wistar-Kyoto (WKY) rats $(n=74)$ obtained from Janvier (France) were housed under a 12-h day/night cycle and had free access to food and water before and after surgery.

\section{EXPERIMENTAL MESENTERIC ISCHEMIA}

Rats were anesthetized with sodium pentobarbitone $(40 \mathrm{mg} / \mathrm{Kg}$; i.p.) and the ventral abdomen was shaved and washed with $10 \%$ povidone iodine. To produce analgesia, buprenorphine $(0.01 \mathrm{mg} / \mathrm{Kg})$ was administered subcutaneously $30 \mathrm{~min}$ prior to anesthesia and $12 \mathrm{~h}$ after surgery. Adequacy of anesthesia was confirmed by total absence of reflex responses (pinching the tail, pedal withdrawal, and pupillary reflex). Abdominal cavity was accessed by a midline incision and the superior mesenteric artery was visualized and clamped. Pulselessness of mesenteric arterial branches was achieved immediately after occlusion of the superior mesenteric artery. After a 90-min ischemia, the clamp was removed and the midline incision was closed. Rats were allowed to recover from anesthesia and placed back into their cages with free access to food and water. Sham-operated (SO) animals underwent the same surgical procedure with the exception of the clamping.

Following $24 \mathrm{~h}$ (reperfusion time), rats were anesthetized with sodium pentobarbitone ( $40 \mathrm{mg} / \mathrm{Kg}$; i.p.), decapitated, and the mesenteric arcade placed in cold physiological salt solution (PSS) of the following composition (in $\mathrm{mM}$ ): $\mathrm{NaCl} 112.0 ; \mathrm{KCl} 4.7 ; \mathrm{CaCl}_{2}$ 2.5; $\mathrm{KH}_{2} \mathrm{PO}_{4} 1.1 ; \mathrm{MgSO}_{4}$ 1.2; $\mathrm{NaHCO}_{3} 25.0$; and glucose 11.1. In some anesthetized rats, blood samples $(2 \mathrm{ml})$ were collected by cardiac puncture and plasma was separated by centrifugation at $12000 \times g, 5 \mathrm{~min}, 4^{\circ} \mathrm{C}$, aliquoted, and stored at $-70^{\circ} \mathrm{C}$.
The duration of I/R used was based on previous studies where we observed middle cerebral artery structural, mechanical, and myogenic changes (Cipolla et al., 1997; Jiménez-Altayó et al., 2007,2009 ) as well as mesenteric functional alterations (MartínezRevelles et al., 2011) after $90 \mathrm{~min}$ occlusion followed by $24 \mathrm{~h}$ reperfusion.

\section{TREATMENT WITH A DUAL ET RECEPTOR ANTAGONIST}

The effect of i.p. injection of tezosentan (TZS, $10 \mathrm{mg} / \mathrm{Kg}$ dissolved in saline) on some of the parameters studied was studied in both $\mathrm{IO}$ and SO rats. The ET receptor antagonist was administered $1 \mathrm{~h}$ before starting the surgical procedure described above, using a dose that has been described as having positive effects on mesenteric I/R (Lugowska-Umer et al., 2008).

\section{TISSUE PREPARATION}

Segments of third-order branches (pressure myography, superoxide anion $\left(\mathrm{O}_{2}^{-}\right)$production, immunofluorescence and vessel culture studies) and second- and third-order branches (qRT-PCR) of the mesenteric tree were dissected free of fat and connective tissue and maintained in PSS at $4^{\circ} \mathrm{C}$, continuously gassed with 95\% $\mathrm{O}_{2}$ and $5 \% \mathrm{CO}_{2}$. Vessels to be used for $\mathrm{O}_{2}^{-}$production were placed in PSS containing 30\% sucrose overnight. Next, the vessels were transferred to a cryomold (Bayer Química Farmacéutica, Barcelona, Spain) containing Tissue-Tek OCT embedding medium (Sakura Finetek Europe, Zoeterwoude, The Netherlands) for $20 \mathrm{~min}$, and then immediately frozen in liquid nitrogen. For immunofluorescence studies, vessels were fixed with $4 \%$ phosphate buffered paraformaldehyde (PFA, $\mathrm{pH}=7.4$ ) for $1 \mathrm{~h}$ and washed in three changes of phosphate buffered saline solution (PBS, $\mathrm{pH}=7.4$ ). After clearing, arterial segments were placed in PBS containing 30\% sucrose overnight, transferred to a cryomold containing Tissue-Tek OCT embedding medium and frozen in liquid nitrogen. Second- and third-order branches that will be used for qRT-PCR were frozen in liquid nitrogen immediately after dissection. All samples frozen in liquid nitrogen were kept at $-70^{\circ} \mathrm{C}$ until the day of the experiments. Finally, segments of third-order branches from a group of non-operated rats were incubated in culture medium.

\section{DETERMINATION OF ET-1 PLASMA LEVELS}

ET-1 was analyzed by commercial ELISA kit (Biomedica Medizinprodukte $\mathrm{GmbH}$, Wien, Austria) according to the manufacturer's instruction. Results are expressed as pg/ml.

\section{PRESSURE MYOGRAPHY}

Structural and mechanical properties of MRA were studied with a pressure myograph (Danish Myo Tech Model P100; J. P. Trading I/S, Aarhus, Denmark), as described previously (Briones et al., 2003; Jiménez-Altayó et al., 2007, 2009). Briefly, the third-order vessel was placed between two glass microcannulas and secured with surgical nylon suture. After the small branches were tied off, vessel length was adjusted so that the vessel walls were parallel without stretch. Intraluminal pressure was then raised to $140 \mathrm{mmHg}$, and the artery was unbuckled by adjusting the cannula. Afterward, the artery was left to equilibrate $(1 \mathrm{~h})$ at $70 \mathrm{mmHg}$ in gassed calcium-free PSS $\left(0 \mathrm{Ca}^{2+}\right.$ : omitting calcium and adding 
10 mM EGTA; Sigma-Aldrich, St Louis, MO, USA) at $37^{\circ} \mathrm{C}$. Intraluminal pressure was reduced to $3 \mathrm{mmHg}$, and a pressure-diameter curve (3-120 $\mathrm{mmHg}$ ) was obtained. Internal and external diameters $\left(D \mathrm{i}_{0 \mathrm{Ca}}, D \mathrm{e}_{0 \mathrm{Ca}}\right)$ were measured for $3 \mathrm{~min}$ at each intraluminal pressure. The resolution of the measurements is $1 \mu \mathrm{m}$. Finally, the artery was set to $70 \mathrm{mmHg}$ in $0 \mathrm{Ca}^{2+}$-PSS, pressure-fixed with $4 \%$ PFA for $45 \mathrm{~min}$, and stored in PFA (4\%) at $4^{\circ} \mathrm{C}$ until analysis of nuclei distribution and elastin content and organization by confocal microscopy were performed. All the experiments were carried out in MRA from SO and ischemic (IO) rats.

\section{CALCULATION OF STRUCTURAL AND MECHANICAL PARAMETERS}

Wall thickness (WT), cross-sectional area (CSA), and wall/lumen $(\mathrm{W} / \mathrm{L})$ ratio were calculated as follows: $\mathrm{WT}=\left(D \mathrm{e}_{0 \mathrm{Ca}}-D \mathrm{i}_{0 \mathrm{Ca}}\right) / 2$; $\mathrm{CSA}=(\pi / 4) \times\left[\left(D \mathrm{e}_{0 \mathrm{Ca}}\right)^{2}-\left(\mathrm{Di}_{0 \mathrm{Ca}}\right)^{2}\right] ; \quad$ and $\mathrm{W} / \mathrm{L}=\left(D \mathrm{e}_{0 \mathrm{Ca}}-\right.$ $\left.D \mathrm{i}_{0 \mathrm{Ca}}\right) / 2 D \mathrm{i}_{0 \mathrm{Ca}}$, where $D \mathrm{e}_{0 \mathrm{Ca}}$ and $D \mathrm{i}_{0 \mathrm{Ca}}$ are the external and internal diameter observed for a given intravascular pressure in passive conditions $\left(0 \mathrm{Ca}^{2+}\right)$, respectively. Mechanical parameters were calculated as described by Baumbach and Heistad (1989). Circumferential wall strain $(\varepsilon)$ was calculated as $\left(D \mathrm{i}_{0 \mathrm{Ca}}-D \mathrm{o}_{0 \mathrm{Ca}}\right) / \mathrm{Do}_{0 \mathrm{Ca}}$, where $\mathrm{Do}_{0 \mathrm{Ca}}$ is the internal diameter at $3 \mathrm{mmHg}$, measured under relaxed conditions. Circumferential wall stress $(\sigma)$ was calculated as $\left(P \times \mathrm{Di}_{0 \mathrm{Ca}}\right) / 2 \mathrm{WT}$, where $\mathrm{P}$ is the intraluminal pressure $\left(1 \mathrm{mmHg}=133.4 \mathrm{Nm}^{-2}\right)$ and WT is thickness of the vessel wall at each intraluminal pressure in $0 \mathrm{Ca}^{2+}$ medium. Elastic modulus was calculated by fitting stress-strain data to $\sigma=\sigma_{\text {orig }} \exp (\beta \varepsilon)$, where $\sigma_{\text {orig }}$ is the stress at the original diameter $(3 \mathrm{mmHg})$. The $\beta$ value was used as an index of wall stiffness (Mulvany and Aalkjaer, 1990).

\section{NUCLEI DISTRIBUTION BY CONFOCAL MICROSCOPY}

Pressured-fixed intact arteries were stained with the nuclear dye Hoechst 33342 (10 $\mu \mathrm{g} / \mathrm{ml}$; Sigma-Aldrich) for $30 \mathrm{~min}$. After washing was completed, arteries were mounted on slides with a well made of silicon spacers to avoid artery deformation. They were visualized with a Leica TCS SP2 (Heidelberg, Germany) confocal system fitted with an inverted microscope and argon and heliumneon laser sources with an oil-immersion lens $[\times 63$; excitation (Ex) 351-364 nm and emission (Em) 400-500 nm]. Stacks of serial optical slices $(0.5 \mu \mathrm{m}$ thick) were captured from the adventitia to the lumen of each artery. Two stacks of images of several regions were captured in each arterial segment. Individual images of the endothelial layer were also captured. MetaMorph Image Analysis software (Molecular Devices, Sunnyvale, CA, USA) was used for quantification. The nuclei number was measured in the $Z$-axis, as previously described (Jiménez-Altayó et al., 2007). To allow comparison of SO and IO rats, the following calculations were performed: WT $(\mu \mathrm{m})$, measured as adventitial thickness + media thickness; number of adventitial, smooth muscle, and endothelial cell nuclei was calculated per area $\left(\mathrm{mm}^{2}\right)$ per stack.

\section{ELASTIN CONTENT AND ORGANIZATION BY CONFOCAL MICROSCOPY}

The content and organization of elastic fibers in the internal elastic lamina (IEL) were studied in intact pressure-fixed MRA using a Leica TCS SP2 confocal microscope on the basis of the autofluorescent properties of elastin (Ex $488 \mathrm{~nm}$ and Em 500-560 nm; 46). Stacks of serial optical sections $(0.3 \mu \mathrm{m}$ thick) were captured from each artery with an $\times 63$ oil-immersion objective using the $488-\mathrm{nm}$ line of the confocal microscope. Two stacks of images of several regions were captured in each arterial segment. All the images were taken under identical conditions of zoom $(\times 1)$, laser intensity, brightness, and contrast.

Quantitative analysis was performed with MetaMorph Image Analysis software as reported previously (Jiménez-Altayó et al., 2007). From each stack of serial images, individual projections of the IEL were reconstructed, and total number and area of fenestrae were measured. Fluorescence intensity values were used as estimate of elastin concentration, as previously described, following the assumption that the concentration of elastin has a linear relationship with fluorescence intensity (Blomfield and Farrar, 1969).

\section{IMMUNOFLUORESCENCE}

Frozen sections $(14 \mu \mathrm{m})$ were incubated with a rabbit polyclonal antibody against collagen I/III (1:30; Calbiochem, Pacific Center Court, San Diego, CA, USA) or a mouse monoclonal antibody against ET-1 (1:100; Thermo Scientific, Rockford, IL, USA). After washing, rings were incubated with the secondary antibody, donkey anti-rabbit (1:200), or donkey anti-mouse (1:200) IgG conjugated to $\mathrm{Cy}^{\mathrm{TM}} 3$ (Jackson ImmunoResearch Laboratories Inc., West Grove, PA, USA). After washing, immunofluorescent signals were viewed using an inverted Leica TCS SP2 confocal laser scanning microscope with oil-immersion lens $(\times 63)$. $\mathrm{Cy}^{\mathrm{TM}} 3$ labeled antibody was visualized by excitation at $568 \mathrm{~nm}$ and detection at 600-700 nm.

The specificity of the immunostaining was evaluated by omission of the primary antibody and processed as above. Under these conditions, no staining was observed in the vessel wall in any experimental situation.

Quantitative analysis of fluorescence was performed with MetaMorph Image Analysis software. The region of interest (ROI), as marked in Figure 3 with a dotted white line, was carefully drawn around the inner and outer edges of the vessel wall. The intensity of fluorescence per area within each ROI was measured in two rings of each animal and the results were expressed as arbitrary units. All measurements were conducted blind. Images of the natural autofluorescence of elastin were also taken. Autofluorescence was visualized by excitation at $488 \mathrm{~nm}$ and detection at $490-535 \mathrm{~nm}$.

\section{REAL-TIME QUANTITATIVE RT-PCR}

Total RNA (tRNA) was isolated using Trizol (TRI Reagent) from frozen MRA according to the manufacturer's protocol. tRNA quality was evaluated by electrophoresis on a denaturing agarose gel ( $1 \%)$; tRNA concentration and purity were determined by measuring absorbance at 260 and $280 \mathrm{~nm}$ by spectrophotometry (Nanodrop ND 1000, Thermo Scientific). The samples with intact ribosomal RNA bands and with A260/A280 ratio between 1.8 and 2.0 were used for complementary DNA (cDNA) synthesis.

Using a commercial kit (High-Capacity cDNA Reverse Transcription Kit, Applied Biosystems, Foster City, CA, USA), following the manufacturer's instructions, $1 \mu \mathrm{g}$ of tRNA was inversely transcribed to cDNA in $25 \mu \mathrm{l}$ reaction volume, containing reaction buffer, deoxynucleoside triphosphate (dNTPs), aleatory probes, Reverse Transcriptase (MultiScribe reverse Transcriptase), and 
DEPC-treated water. The reaction takes place in a thermocycler (Peltier Thermal Cycler PTC-200, Bio-Rad, Hercules, CA, USA) for $10 \mathrm{~min}$ at $25^{\circ} \mathrm{C}$ (Anneal step), following of an extension step at $37^{\circ} \mathrm{C}$ for $2 \mathrm{~h}$ and a final step at $85^{\circ} \mathrm{C}$ for $5 \mathrm{~min}$ (Heatinactivation). Gene expression for the subunits of $\mathrm{NAD}(\mathrm{P}) \mathrm{H}$ oxidase, Nox-1, p22 $2^{\text {phox }}$, and $\mathrm{p} 47^{\mathrm{phox}}$, were quantified by quantitative real-time PCR based on Sybr-Green fluorescence using the $18 \mathrm{~S}$ ribosomal subunit of RNA as internal control with a GeneAmp 7500 PCR system (Applied Biosystems) following the manufacturer's instructions: first step of polymerase activation at $95^{\circ} \mathrm{C}$ for $10 \mathrm{~min}$ and 40 cycles composed of 2 steps, denaturing at $95^{\circ} \mathrm{C}$ for $15 \mathrm{~s}$ and anneal/extension at $60^{\circ} \mathrm{C}$ for $1 \mathrm{~min}$. The specific primer sequences for rodent were: 18S (Hs99999901 s1); Nox-1 (forward 5'-CCTTCCATAAGCTGGTGGCAT-3' and reverse $5^{\prime}$-GCCATGGATCCCTAAGCAGAT-3'), p22 $2^{\text {phox }}$ (forward: $5^{\prime}$-GGCCATTGCCAGTGTGATCTA-3 $3^{\prime}$ and reverse $5^{\prime}$ TGCTTGATGGTGCCTCCAA-3') and $\mathrm{p} 47^{\mathrm{phox}}$ (forward $5^{\prime}$ AGGAGATGTTCCCCATTGAGG-3' and reverse $5^{\prime}$-CAGTCCCATG AGGCTGTTGAA-3'). Primers were designed from conserved regions of the studied genes. qRT-PCR reactions were set following the manufacture's conditions. Ct values obtained for each gene were referenced to $\mathrm{r} 18 \mathrm{~S}(\Delta \mathrm{Ct})$ and converted to the linear form using the term $2^{-\Delta \mathrm{Ct}}$ as a value directly proportional to the copy number of cDNA and initial quantity of mRNA (Novensa et al., 2010).

\section{VESSEL ORGAN CULTURE}

All MRA were washed three times in PBS supplemented with penicillin $(1000 \mathrm{U} / \mathrm{ml})$ and streptomycin $(1 \mathrm{mg} / \mathrm{ml}$; Pen-Strep). Afterward, vessels were equilibrated for $30 \mathrm{~min}$ in Dulbecco's modified Eagle's medium supplemented with Pen-Strep (200 mM) and $0.001 \%$ fetal calf serum at $37^{\circ} \mathrm{C}$ in an atmosphere of $5 \%$ $\mathrm{CO}_{2}$ in a culture incubator. The medium was then replaced by a fresh medium with or without $1 \mathrm{ng} / \mathrm{ml} \mathrm{ET-1}$ (Alexis biochemicals, Farmingdale, NY, USA) and incubated for 3 or $6 \mathrm{~h}$. Afterward, arteries were prepared for evaluation of $\mathrm{O}_{2}^{--}$production, as indicated above. This organ culture model was chosen to avoid phenotypic alterations of smooth muscle cells, which can occur in cell culture, and to preserve the in vivo cell-to-cell and cell-to-matrix interactions. Vessels were incubated in culture medium in sterile conditions to assess a direct effect of ET- 1 in $\mathrm{O}_{2}^{-}$production without the interference of endotoxin contaminants.

\section{MEASUREMENT OF $\mathbf{0}_{2}^{-}$PRODUCTION}

The oxidative fluorescent dye dihydroethidium (DHE), which in the presence of superoxide anion is oxidized to ethidium bromide, was used to evaluate production of $\mathrm{O}_{2}^{-}$in situ, as described previously (Jiménez-Altayó et al., 2006; Martinez-Revelles et al., 2008). Briefly, frozen tissue segments were cut into $14 \mu \mathrm{m}$ thick sections and placed on a glass slide. Serial sections were equilibrated under identical conditions for $30 \mathrm{~min}$ at $37^{\circ} \mathrm{C}$ in Krebs-HEPES buffer (in mM: $\mathrm{NaCl} 130, \mathrm{KCl} 5.6, \mathrm{CaCl}_{2} 2, \mathrm{MgCl}_{2}$ 0.24, HEPES 8.3, glucose 11, pH 7.4). Fresh buffer containing DHE $(2 \mu \mathrm{M})$ was applied topically onto each tissue section, cover-slipped, and incubated for $30 \mathrm{~min}$ in a light-protected humidified chamber at $37^{\circ} \mathrm{C}$, and then ethidium bromide fluorescence (Ex $488 \mathrm{~nm}$ and $\mathrm{Em} 610 \mathrm{~nm}$ ) was viewed by confocal laser scanning microscopy $(\times 63)$, using the same imaging settings in each case. Quantitative analyses of $\mathrm{O}_{2}^{--}$production was performed with MetaMorph Image Analysis software. The ROI, as marked in Figure 5 with a dotted white line, was carefully drawn around the inner and outer edges of the vessel wall. The intensity of fluorescence per area within each ROI was measured in two rings of each animal and the results were expressed as arbitrary units. All measurements were conducted blind.

\section{STATISTICAL ANALYSIS}

Results are expressed as mean \pm SEM of the number of rats. Treatment dependence of structural or mechanical properties was assessed using two-way (pressure, treatment) analysis of variance (ANOVA), with repeated measures on the pressure factor. In the case of a single factor, unpaired Student's $t$-test was used. Data analysis was carried out using GraphPad Prism v4. A value of $P<0.05$ was considered significant.

\section{RESULTS}

Body weight was measured before $(0 \mathrm{~h})$ and after $(24 \mathrm{~h})$ surgery. Similar body weights were observed in SO ( $0 \mathrm{~h}: 338 \pm 8.40 \mathrm{~g}$; $24 \mathrm{~h}: 323.39 \pm 8.22 \mathrm{~g}, n=31)$, IO ( $0 \mathrm{~h}: 352.77 \pm 9.90 \mathrm{~g} ; 24 \mathrm{~h}$ : $335.69 \pm 9.30 \mathrm{~g}, n=26)$, and IO + TEZ ( $0 \mathrm{~h}: 360.86 \pm 10,70 \mathrm{~g}$; $24 \mathrm{~h}: 350.14 \pm 10.79 \mathrm{~g}, n=7)$ rats. Plasma levels of ET-1 were enhanced at $24 \mathrm{~h}$ after onset of reperfusion (SO: $5.30 \pm 0.69 \mathrm{pg} / \mathrm{ml}$; IO: $13.29 \pm 2.41 \mathrm{pg} / \mathrm{ml}, n=5-7 ; P<0.05)$.

\section{EFFECT OF MESENTERIC I/R ON VASCULAR STRUCTURE AND MECHANICS}

Increase of intraluminal pressure markedly augments lumen and vessel diameters in MRA. Changes in vessel diameter (Figure 1A) were slightly greater in IO compared to SO rats, while no differences were observed in changes in lumen diameter (Figure 1B). As
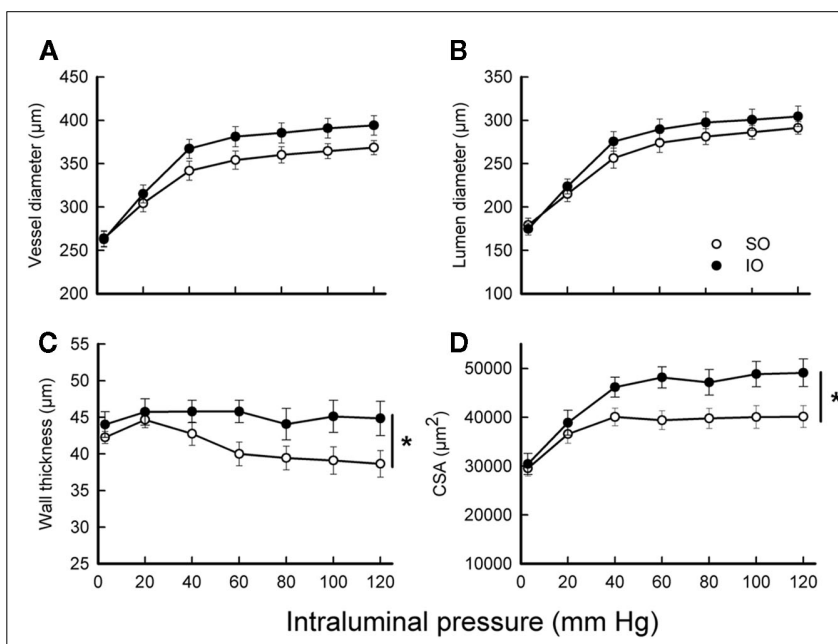

FIGURE 1 | Effect of mesenteric I/R on structural parameters from fully relaxed rat mesenteric resistance arteries. (A) Vessel diameter-intraluminal pressure. (B) Lumen diameter-intraluminal pressure. (C) Wall thickness-intraluminal pressure. (D) Cross-sectional area (CSA)-intraluminal pressure. Values are the mean \pm SEM of $n=9-10$. ${ }^{*} P<0.05$ by two-way ANOVA. 

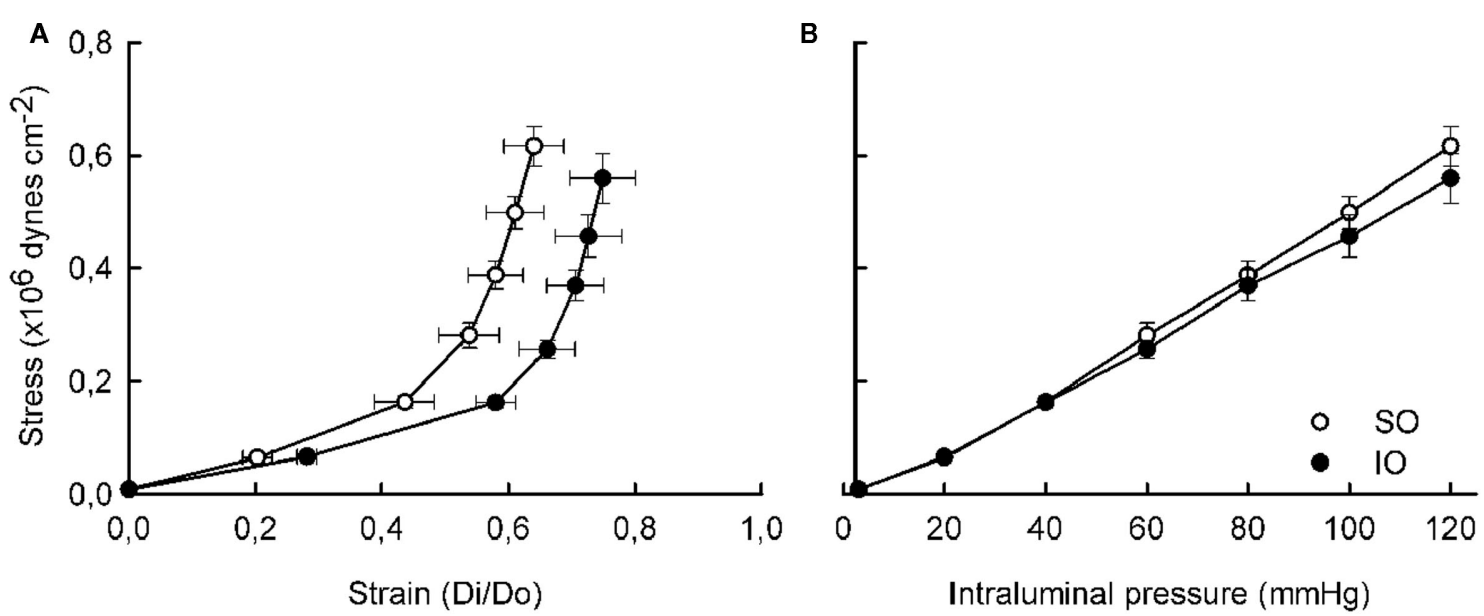

FIGURE 2 | Effect of mesenteric I/R on mechanical properties from fully relaxed rat mesenteric resistance arteries. (A) Stress-strain (Di/Do). (B) Wall stress-intraluminal pressure. Do, internal diameter at $3 \mathrm{mmHg}$; Di, observed internal diameter from a given intravascular pressure. Values are the mean $\pm \mathrm{SEM}$ of $n=9-10$.

Table 1 | Comparison of morphological parameters in pressurized segments of mesenteric resistance artery from $\mathrm{SO}$ and $\mathrm{IO}$ rats.

\begin{tabular}{lll}
\hline & So & IO \\
\hline Wall thickness $(\mu \mathrm{m})$ & $24.45 \pm 0.62$ & $32.11 \pm 2.84^{*}$ \\
Adventitial thickness $(\mu \mathrm{m})$ & $10.17 \pm 0.35$ & $14.62 \pm 2.64$ \\
Media thickness $(\mu \mathrm{m})$ & $14.29 \pm 0.69$ & $17.5 \pm 1.30^{*}$ \\
Number of $\mathrm{AC} / \mathrm{mm}^{2}$ & $2251.09 \pm 171.64$ & $3014.71 \pm 464.85$ \\
Number of $\mathrm{SMC} / \mathrm{mm}^{2}$ & $6071 \pm 170$ & $6300 \pm 240$ \\
Number of $\mathrm{EC} / \mathrm{mm}^{2}$ & $1870 \pm 60$ & $1999 \pm 76$
\end{tabular}

Pressured $(70 \mathrm{mmHg})$-fixed intact arteries were incubated with $0.01 \mathrm{mg} / \mathrm{ml}$ Hoechst 33342 to stain cell nuclei. The images were taken from slide-mounted vessels with a $\times 63$ oil-immersion objective, zoom $\times 1$, with a laser scanning confocal microscope. Values are means $\pm S E M$ of $n=7$. AC, adventitial cells; $S M C$, smooth muscle cells; EC, endothelial cells. ${ }^{*} P<0.05$ SO vs. 10 by unpaired Student's t-test.

a consequence, changes of WT (Figure 1C) and CSA (Figure 1D) with increasing pressure were higher $(P<0.05)$ in MRA from IO compared with SO rats. Nevertheless, W/L was not modified after mesenteric I/R (not shown).

To determine the effect of mesenteric $I / R$ in passive mechanical properties of the vascular wall, stiffness, and wall stress were analyzed. MRA from IO rats showed decreased stiffness (increased distensibility), as evidenced by the smaller value of $\beta$ (SO: $6.8 \pm 0.5$, $n=10$; IO: $5.6 \pm 0.2, n=9 ; P<0.05)$ and the rightward shift of the stress-strain relationship (Figure $2 \mathbf{A}$ ). In contrast, wall stress (Figure 2B) was similar in arteries from both groups of rats.

\section{CHANGES INDUCED BY MESENTERIC I/R ON VASCULAR MORPHOLOGY}

The morphological measurements from intact vessels by confocal microscopy are reported in Table 1 . After $\mathrm{I} / \mathrm{R}$, wall and media thickness were increased $(P<0.05)$, but adventitia thickness and the number of adventitial, smooth muscle, and endothelial cells was not significantly modified (Table 1). Furthermore, the length and width of smooth muscle cell nuclei were similar in vessels from SO and IO animals (not shown).

\section{EFFECT OF MESENTERIC I/R IN COLLAGEN EXPRESSION AND ELASTIN CONTENT AND ORGANIZATION}

In MRA from SO animals, collagen type I and III, the major collagen types found in arteries, were mainly expressed in the outer layer coinciding with the adventitia (Figure 3A). After I/R, a marked increase of collagen I/III immunofluorescence was seen in all three layers of the vascular wall (Figure 3A). Quantification of the fluorescent signal (Figure 3B) showed an increase $(P<0.01)$ in vessels from IO rats reflecting that collagen I/III production was enhanced after I/R.

The IEL maximal intensity projections from SO and IO rats can be seen in Figure 3C. Quantification of the IEL characteristics showed that the total fenestrae number was increased $(P<0.05)$ after I/R (Figure 3D). Nevertheless, IEL thickness (SO: $6.3 \pm 0.3 \mu \mathrm{m}$; IO: $6.4 \pm 0.3 \mu \mathrm{m}, n=5-6)$, average fluorescence intensity per pixel (SO: $61.2 \pm 6.6$; IO: $70.9 \pm 6.9, n=5-6$ ) and fenestrae area (SO: $20.2 \pm 1.8 \mu \mathrm{m}^{2}$; IO: $17.7 \pm 0.9 \mu \mathrm{m}^{2}, n=5-6$ ) were not modified by I/R.

\section{EFFECT OF MESENTERIC I/R ON ET-1 EXPRESSION}

Fluorescent signal for protein expression of ET-1 was slightly detected in the endothelial and adventitial layer of rings from SO animals but increased $(P<0.05)$ after I/R (Figure 4 ).

\section{INFLUENCE OF MESENTERIC I/R OR ET-1 IN $\mathbf{0}_{\mathbf{2}}^{--}$PRODUCTION}

Low ethidium bromide fluorescence was observed in MRA wall from $\mathrm{SO}$ rats (Figure 5A). After I/R, the level of fluorescence was increased $(P<0.01)$ along the vessel wall (Figure 5B), suggesting an increase of $\mathrm{O}_{2}^{-}$production by $\mathrm{I} / \mathrm{R}$.

After a 3-or 6-h incubation period with culture medium, weak ethidium bromide fluorescence was observed along the MRA wall (Figure 5C). However, the fluorescent signal was increased all over 

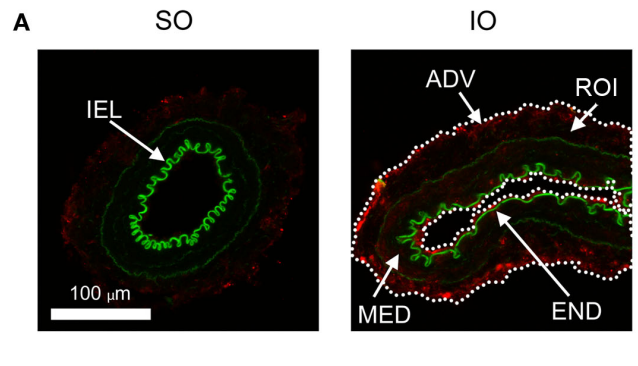

B
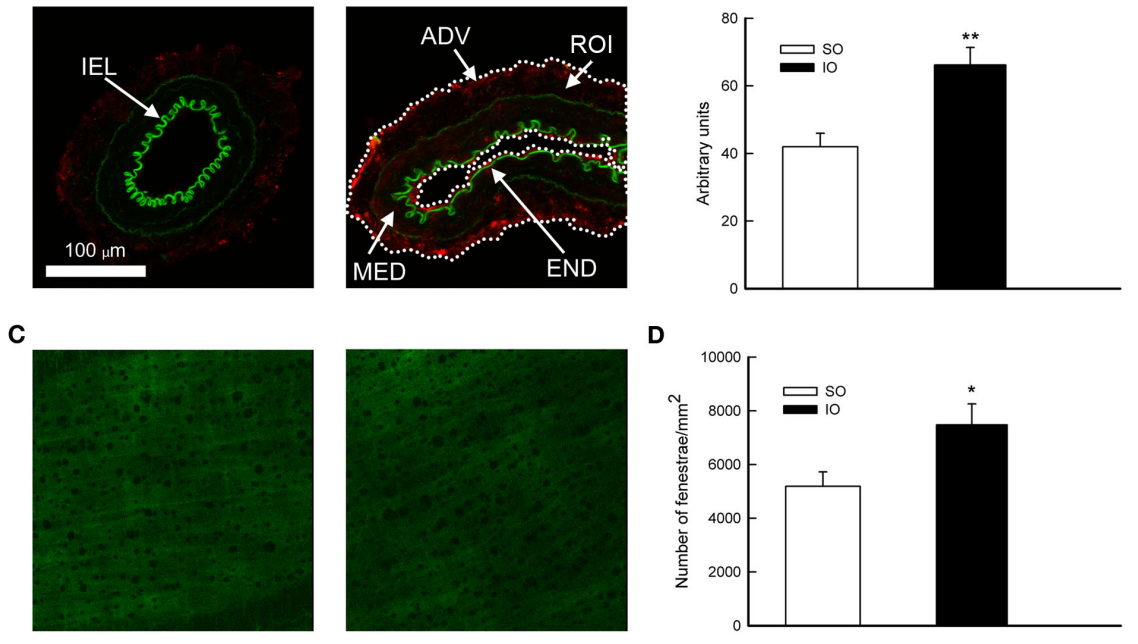

FIGURE 3 | (A) Representative photomicrographs and (B) quantification of collagen I/III immunofluorescence of confocal microscopic sections of mesenteric resistance arteries from $\mathrm{SO}$ and $\mathrm{IO}$ rats. ADV, adventitial layer; END, endothelial layer; MED, media layer; IEL, internal elastic lamina; ROI, region of interest (marked with a dotted white line). (C) Confocal projections of the IEL and (D) quantitative analysis of total number of fenestrae in the IEL of mesenteric resistance arteries from SO and $1 \mathrm{O}$ rats. In (C,D) vessels were pressure-fixed at $70 \mathrm{mmHg}$ and mounted intact on a slide. Projections were obtained from serial optical sections captured with a fluorescence confocal microscope $(\times 63$ oil-immersion objective, zoom $\times 1)$. Image size,

$238 \mu \mathrm{m} \times 238 \mu \mathrm{m}$. Values are the mean \pm SEM of $n=5-6$. ${ }^{*} P<0.05$ by unpaired Student's $t$-test. the vessel wall after either $3(P<0.05)$ or $6 \mathrm{~h}(P<0.01)$ incubation with ET-1 (Figure 5D), reflecting an increase in $\mathrm{O}_{2}^{-}$production.

Analysis of mRNA levels of $\mathrm{NAD}(\mathrm{P}) \mathrm{H}$-oxidase subunits (major source of vascular $\mathrm{O}_{2}^{-}$) shows that Nox-1, p22 phox , and $\mathrm{p} 47^{\mathrm{phox}}$ were present in MRA and marked enhanced $(P<0.05)$ after I/R (Figure 6).

\section{PROTECTIVE EFFECTS OF TEZOSENTAN AGAINST I/R INDUCED CHANGES}

In SO animals, pre-treatment with tezosentan had no effect on any of the parameters studied (results not shown, $n=4$ ).

Tezosentan administration prevented the increase in vessel diameter (Figure 7A), WT (Figure 7C), and CSA (Figure 7D) observed in MRA after I/R. The endothelin receptor antagonist not only prevented the increase in WT and CSA in IO rats, but also significantly decreased those parameters compared to SO rats (Figure 7).

The effect of the dual endothelin antagonist on the mechanical properties of the vascular wall was also determined. The decrease of MRA stiffness observed after I/R was not modified by tezosen$\tan (\mathrm{TZS})$ treatment, as evidenced by the $\beta$ value (SO: $4.9 \pm 0.01$, $n=8$; IO: $4.4 \pm 0.18, n=6$; IO + TZS: $4.3 \pm 0.09, n=5 ; P<0.01$ SO vs. IO; $P<0.001 \mathrm{SO}$ vs. IO + TZS) and the rightward shift of the stress-strain relationship (Figure 7E). However, tezosentan increased wall stress $(P<0.01)$ in $\mathrm{IO}$ (Figure 7F) but not in $\mathrm{SO}$ rats (results not shown).

Treatment with tezosentan also prevented the increase in collagen I/III expression observed in the vascular wall after I/R (Figures 8A,B). Furthermore, in vessels from IO rats tezosen$\tan$ diminished the increase in the level of ethidium bromide fluorescence (Figure 8C) and the enhanced mRNA levels of

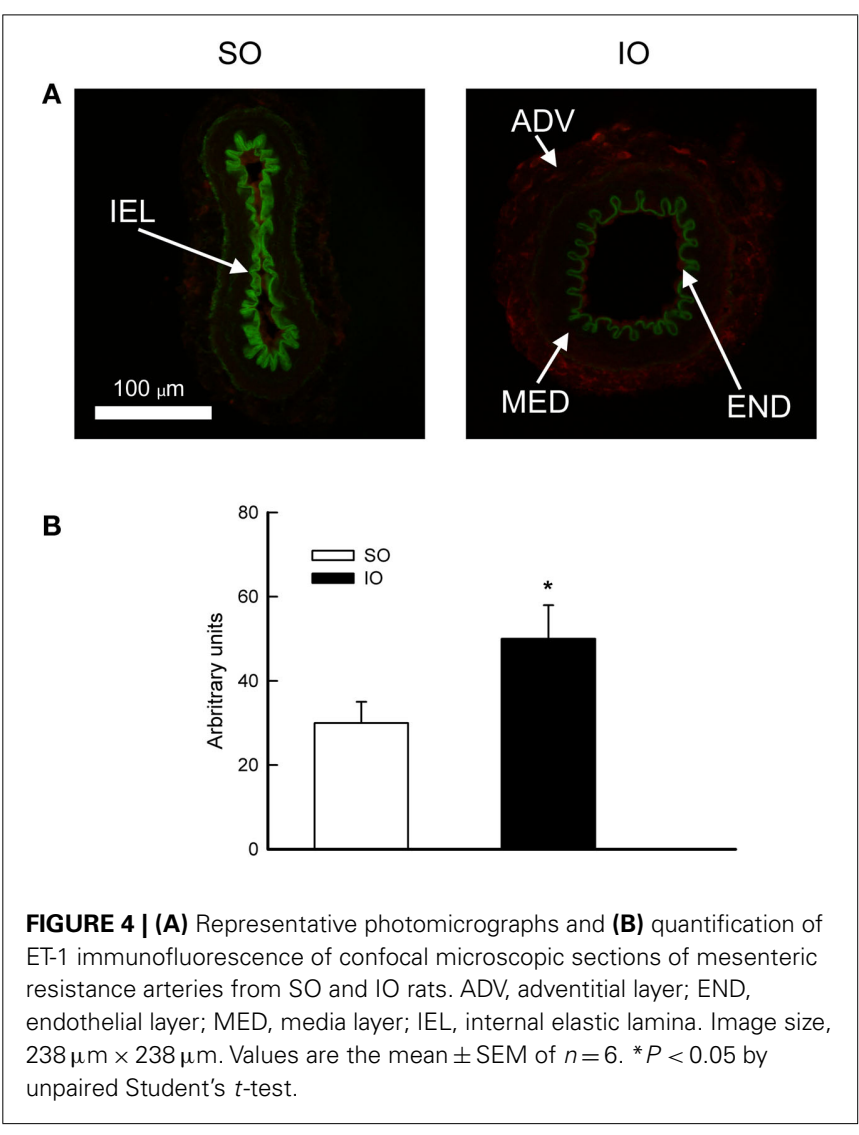

$\mathrm{NAD}(\mathrm{P}) \mathrm{H}$-oxidase subunits Nox-1 and $\mathrm{p} 22^{\text {phox }}$ but not $\mathrm{p} 47^{\text {phox }}$ (Figure 8D). 
A
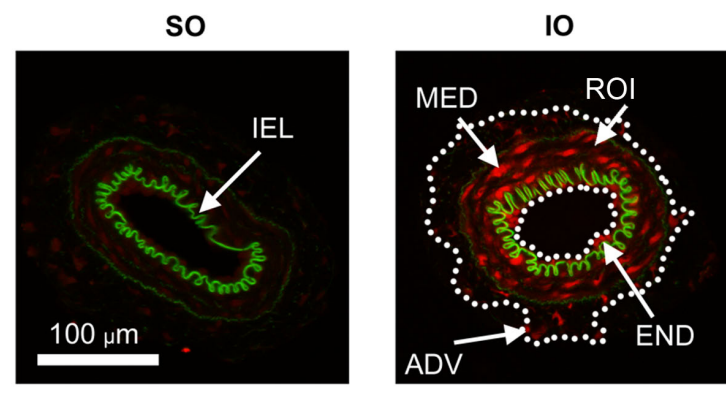

$3 \mathrm{~h}$
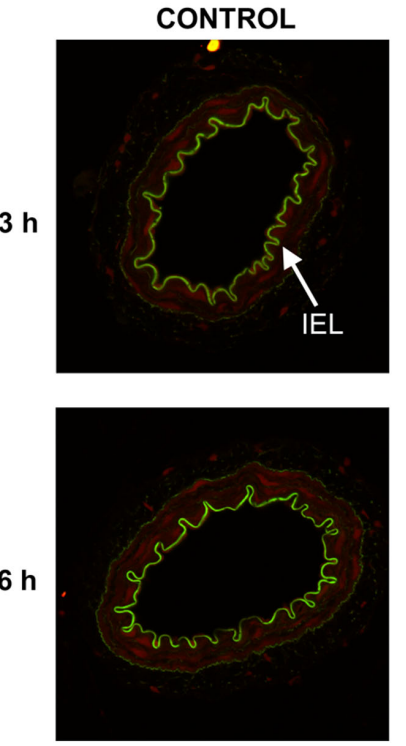
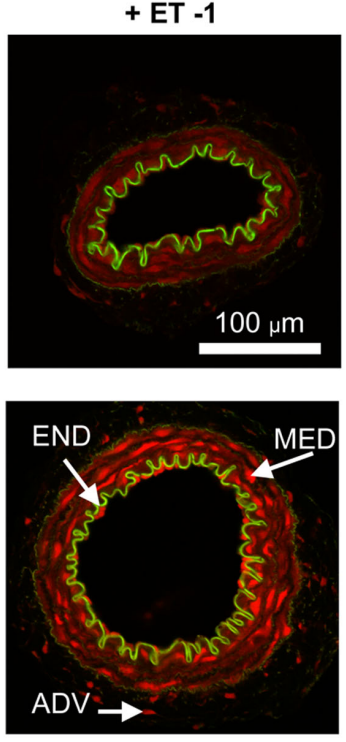

FIGURE 5 | (A,C) Representative photomicrographs and (B,D) quantification of ethidium bromide fluorescence by confocal microscope in sections of mesenteric resistance arteries from $\mathrm{SO}$ and $\mathrm{IO}$ rats (upper panel); or in cultured mesenteric resistance arteries from non-operated rats incubated with or without ET-1

B

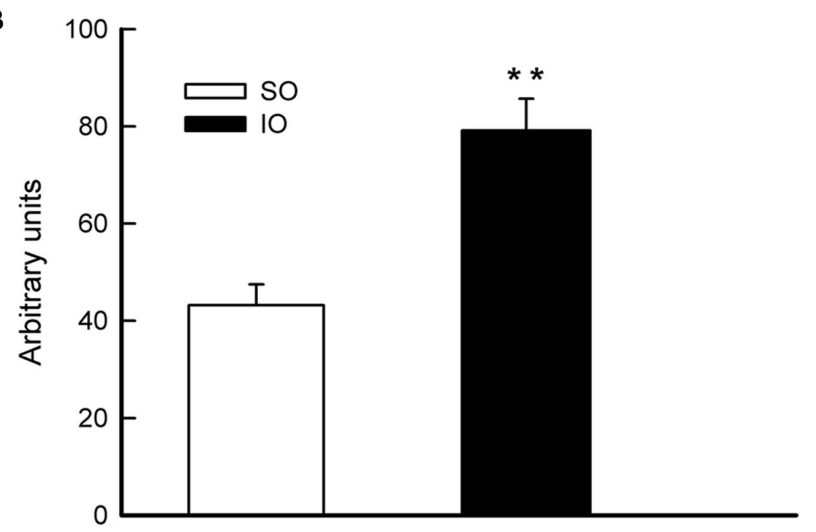

D

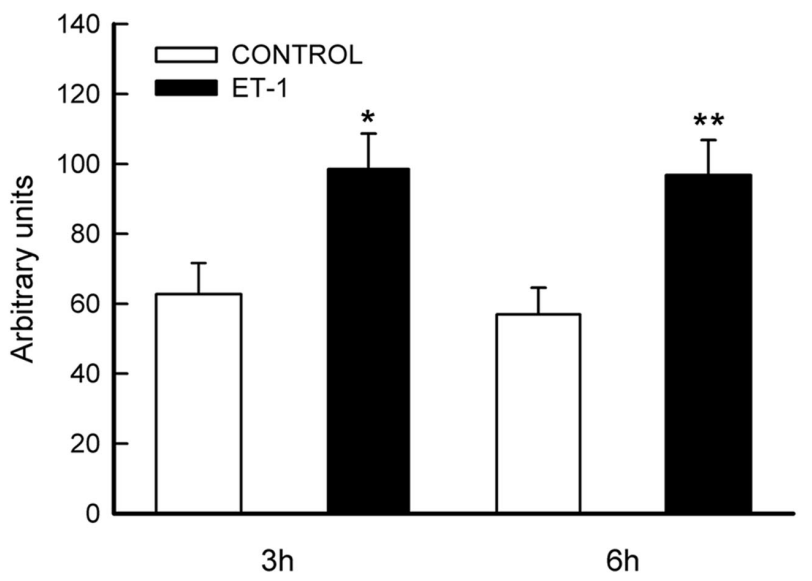

(lower panel). ADV, adventitial layer; END, endothelial layer; MED, media layer; $\mathrm{IEL}$, internal elastic lamina; ROI, region of interest (marked with a dotted white line). Image size, $238 \mu \mathrm{m} \times 238 \mu \mathrm{m}$. Values are the mean $\pm \mathrm{SEM}$ of $n=7-10$. ${ }^{*} P<0.05$; ${ }^{*} P<0.01 \mathrm{SO}$ vs. IO or control vs. ET-1 by unpaired Student's $t$-test.

arterial remodeling did not result in reduced luminal diameter. Recently, it has become evident that development of hypertrophy accompanied by unchanged lumen diameter could contribute to target organ damage (Sonoyama et al., 2007; Khavandi et al., 2009). Changes in arterial wall morphology may be influenced by extracellular matrix (ECM) deposition and/or changes in the number or size of the different cell types. In the present study, we have observed that I/R induce an increase in the WT paralleled by enlargement of the media layer that could not be explained by cell proliferation and growth. Collagen is an important component of the ECM and among different types, collagen type I and III are the most abundant in the vascular wall (Murata et al., 1986). The fact that collagen I/III expression was augmented after I/R seems to explain, at least in part, the observed hypertrophic remodeling. Furthermore, there is a large body of evidence suggesting a key role for oxidative stress in hypertrophic remodeling of blood vessels (Baumbach et al., 2006; Jiménez-Altayó et al., 2009) and heart 


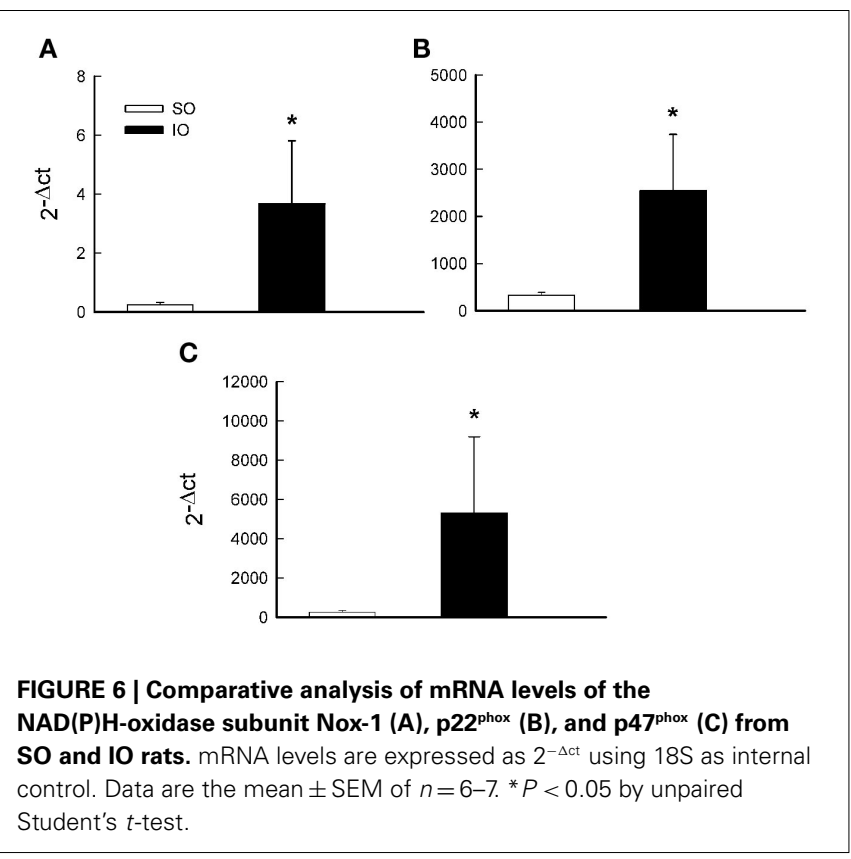

(Takimoto and Kass, 2007). Thus, the increase in $\mathrm{O}_{2}^{-}$production and Nox-1, p22 $2^{\text {phox }}$, and $47^{\text {phox }}$ mRNA levels observed in MRA after I/R lead us to hypothesize that oxidant mechanisms may also be involved in the hypertrophic response.

Vascular mechanical properties like arterial stiffness have an independent predictive value for cardiovascular complications (Laurent et al., 2001; Duprez and Cohn, 2007). In the present study wall stiffness was seen to be reduced after mesenteric I/R. In agreement, decreased stiffness (increased distensibility) was previously reported in middle cerebral artery of WKY rats after cerebral I/R (Jiménez-Altayó et al., 2007). Decreased stiffness may help to avoid lumen narrowing that could occur secondary to hypertrophic remodeling (Intengan and Schiffrin, 2001). Vascular mechanical properties are also influenced by ECM proteins. Generally, collagen contributes to the enhanced stiffness in hypertension (Sharifi et al., 1998; Intengan et al., 1999; Briones et al., 2010). As described above, MRA from ischemic rats showed increased collagen I/III expression yet decreased stiffness. Similar to these findings, other groups have also reported this paradoxical enhancement in compliance despite an increase in collagen, either in subcutaneous arteries from hypertensive individuals (Intengan et al., 1999) or MRA from Type-2 diabetic rats (Sachidanandam et al., 2009). A possible explanation might be that deposition of new collagen could not affect vascular compliance at the time point that was analyzed. In this regard, studies have described an increased deposition of collagen in the early stages of hypertension, even though an increased stiffness only occurs in advanced stages of hypertension (Intengan and Schiffrin, 2001). Therefore, in addition to altered collagen content, its organization may be essential to defining the stiffness of the arterial wall (Intengan and Schiffrin, 2001; Briones et al., 2010).

Another factor that could also be important in determining vascular compliance is the content and organization of elastin (Intengan and Schiffrin, 2001). The present results showed that mesenteric I/R altered the organization but not the content of IEL elastin. Changes in vascular stiffness have also been associated with alterations in IEL fenestrae area (Boumaza et al., 2001; Briones et al., 2003; Jiménez-Altayó et al., 2007). However, our results did not show a significant change in fenestrae area but rather point to new fenestrae formation, since the total number of IEL fenestrae was significantly increased after I/R. Interestingly, increase of distending pressure has been associated to an augmented fenestrae number in carotid arteries from WKY rats, probably by fragmentation of large fenestrations (Boumaza et al., 2001). A similar process might be occurring in mesenteric $\mathrm{I} / \mathrm{R}$, most likely in early stages following reperfusion, where increases in perfusion pressure have been reported (Van der Hoven et al., 2001). We have hypothesized that the observed increase in the total number of IEL fenestrae, without significant changes in their area, might also be associated to increased distensibility. Thus, stress in the vicinity of the fenestrations, especially in large holes, may be many times higher than mean stress of the IEL (Wong and Langille, 1996). It is therefore possible that newly formed fenestrae, smaller in nature, could buffer an excessive stress concentration in the IEL, probably representing an adaptive mechanism, as has been previously suggested in hypertension (Boumaza et al., 2001; Briones et al., 2003).

Plasma levels of ET-1 were elevated after mesenteric I/R, as previously reported (Zhang et al., 2008). ET-1 usually acts as autocrine or paracrine hormone, and therefore tissue levels of ET1 are normally higher than those found in the peripheral blood (Masaki, 2004). Interestingly, our findings demonstrated that the increment in plasma ET-1 levels was paralleled by enhancement of ET-1 expression and $\mathrm{O}_{2}^{--}$production along MRA wall. Moreover, incubation of cultured MRA with ET-1 induced an increase in $\mathrm{O}_{2}^{-}$production suggesting a direct association of increased ET- 1 and $\mathrm{O}_{2}^{-}$generation after I/R. Supporting this hypothesis, the treatment with tezosentan, a dual ET receptor antagonist, prevented the observed increase in $\mathrm{O}_{2}^{-}$production and mRNA levels of $\mathrm{NAD}(\mathrm{P}) \mathrm{H}$-oxidase subunits Nox-1 and $\mathrm{p} 22^{\text {phox }}$ in MRA from IO rats. These findings agree with previous studies indicating that ET-1 increases reactive oxygen species (ROS) production in the vasculature ( $\mathrm{Li}$ et al., 2003; Romero et al., 2009). Thus, while increased plasma ET-1 levels might contribute to the remote organ injury described after mesenteric I/R (Mitsuoka et al., 1999), it is feasible that ET-1 released locally could participate in the $\mathrm{O}_{2}^{-}$formation in MRA. In addition, previous studies showed that antagonism of the $\mathrm{ET}_{\mathrm{A}}$ receptor partially prevented $\mathrm{ECM}$ deposition and matrix metalloproteinase activation in middle cerebral arteries in a Type- 2 diabetes model (Harris et al., 2005). Hence, these evidences could lead us to speculate that the induction of $\mathrm{O}_{2}^{-}$production by ET-1 in MRA might be involved in the hypertrophic response observed after mesenteric I/R. This hypothesis is also supported by studies illustrating that ET-1mediated generation of ROS is associated to cardiac hypertrophy (Xu et al., 2004) and is involved in the hypertrophic pathways in vascular smooth muscle cells (Daou and Srivastava, 2004). In transgenic mice that selectively overexpress ET-1 in the endothelium, ET-1 has been described to induce hypertrophy of MRA in part by a mechanism that involves the activation of vascular $\mathrm{NAD}(\mathrm{P}) \mathrm{H}$-oxidase (Amiri et al., 2004). Corroborating these observations, treatment with tezosentan prevented the increase of 


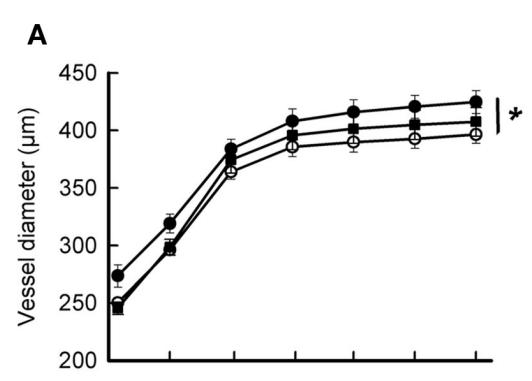

c

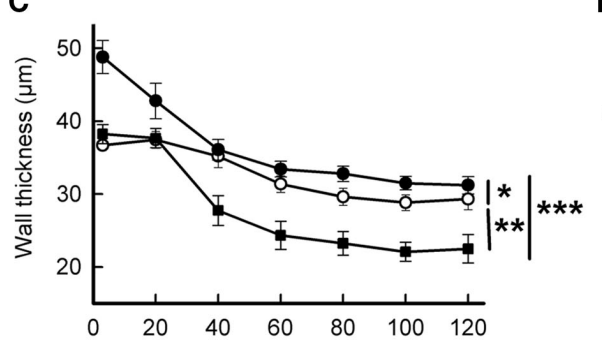

Intraluminal pressure $(\mathrm{mm} \mathrm{Hg})$

E

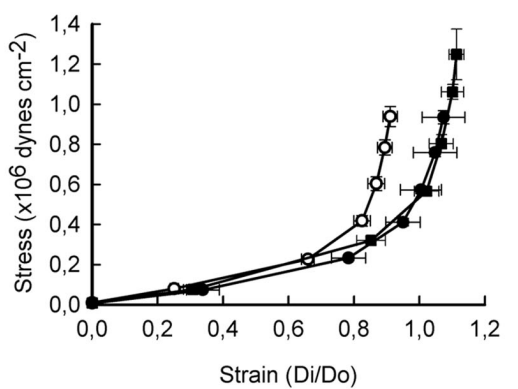

FIGURE 7 | Influence of tezosentan (TZS) treatment on structural and mechanical parameters induced by $I / R$ from fully relaxed mesenteric resistance arteries. (A) Vessel

diameter-intraluminal pressure. (B) Lumen diameter-intraluminal

pressure. (C) Wall thickness-intraluminal pressure. (D) Cross-sectional area
B

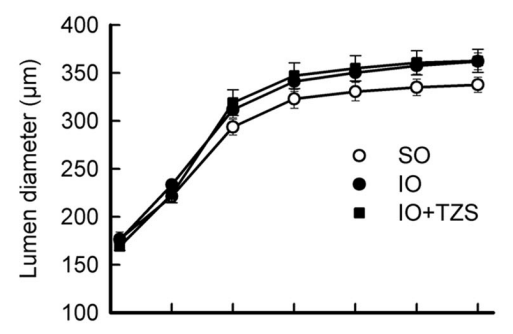

D

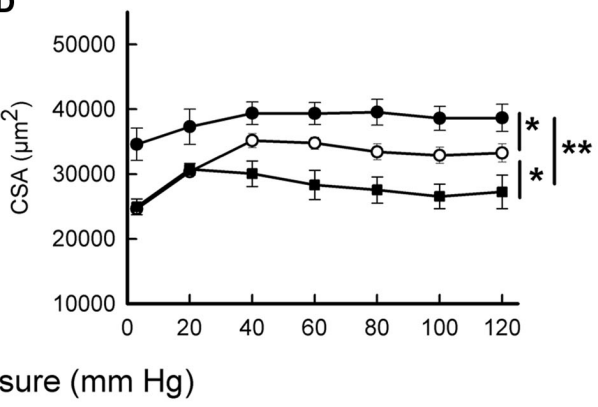

$\mathbf{F}$

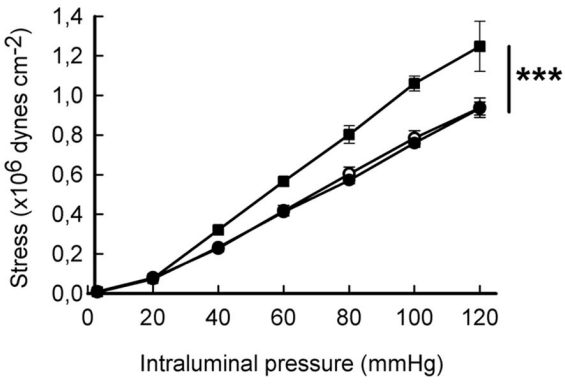

(CSA)-intraluminal pressure. (E) Stress-strain (Di/Do). (F) Wall stress-intraluminal pressure. Do, internal diameter at $3 \mathrm{mmHg}$; Di, observed internal diameter from a given intravascular pressure. Values are the mean \pm SEM of $n=6-8$. ${ }^{*} P<0.05$; ${ }^{*} P<0.01$; ${ }^{*}{ }^{*} P<0.001$ by two-way ANOVA. collagen I/III expression and the hypertrophic remodeling after I/R. Nevertheless, it should be noted that tezosentan treatment not only prevented the hypertrophic remodeling but induced a wall hypotrophy and increase of stress after I/R. Although we do not have a clear explanation for those observations, the effect of tezosentan seems to be linked to I/R, since the ET receptor antagonist was without effect in vessels from SO rats. More experiments are needed to further clarify these unexpected effects of tezosentan after I/R.

In summary, we demonstrate for the first time that 90 min of superior mesenteric artery occlusion followed by $24 \mathrm{~h}$ reperfusion induce MRA structural and mechanical alterations. We show that structural alterations are linked to collagen deposition leading to wall hypertrophy. We demonstrate that the observed increase in ET- 1 is associated to $\mathrm{O}_{2}^{-}$formation contributing to MRA remodeling. We also suggest a relationship between increased IEL fenestrae number and decrease of stiffness, which could represent a mechanism for increasing blood flow. However, decreased stiffness to avoid lumen narrowing may initially be adaptive but become maladaptive associated with wall hypertrophy, thus contributing to target organ damage (Sonoyama et al., 2007; Khavandi et al., 2009). Furthermore, treatment with a dual ET receptor antagonist $1 \mathrm{~h}$ before vessel occlusion might exert beneficial hemodynamic effects after mesenteric I/R through prevention of hypertrophy and preservation of distensibility in MRA. Our study opens up a potential new avenue for reducing the harmful consequences of I/R, implicates ET-1 and oxidative stress in vascular remodeling observed after mesenteric $\mathrm{I} / \mathrm{R}$, and contributes to understanding the mechanism by which ET receptor antagonists exert their beneficial effects on mesenteric I/R (Lugowska-Umer et al., 2008).

\section{ACKNOWLEDGMENTS}

We acknowledge the confocal microscopy core from Universitat Autònoma de Barcelona. This work was supported by Ministerio de Ciencia e Innovación (SAF 2007-60406 to Elisabet Vila). Laura Caracuel was supported by a fellowship from Universitat 
A
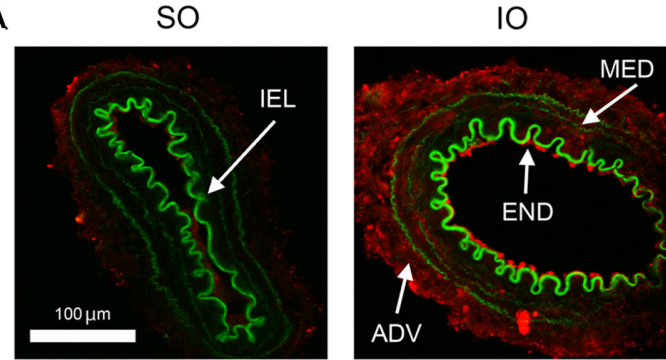

C

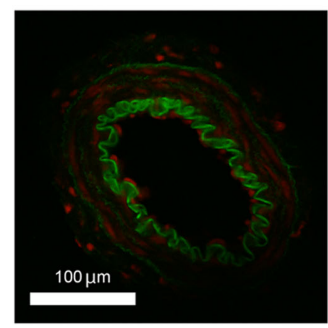

10

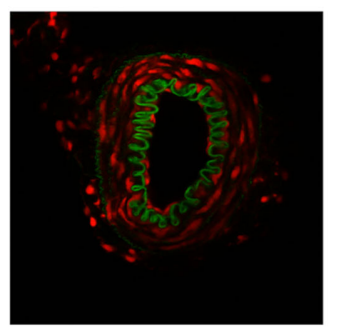

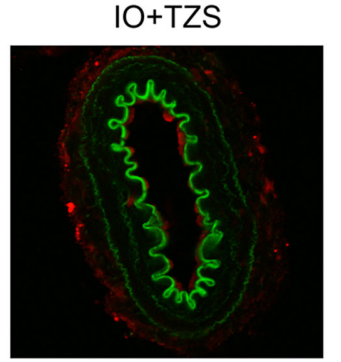

B

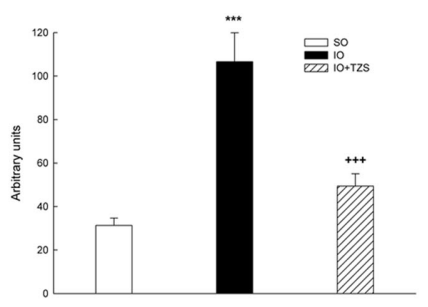

D
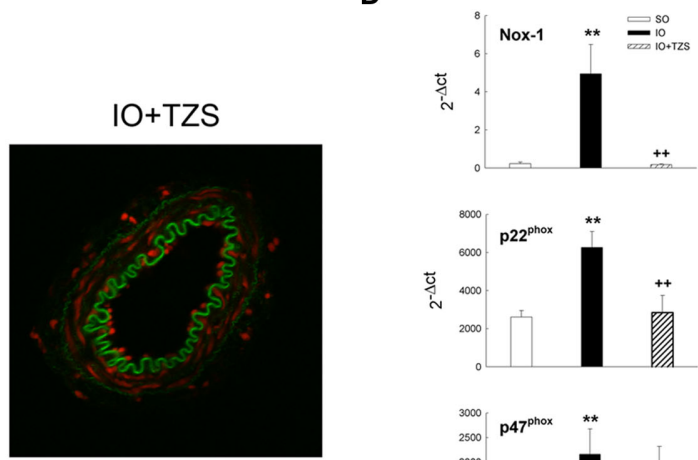

\section{IO+TZS}

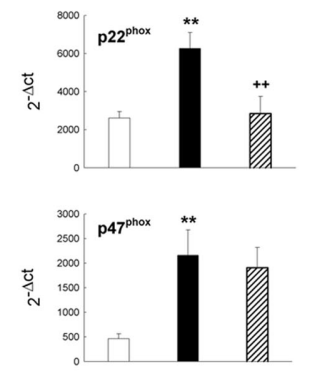

FIGURE 8 | Influence of tezosentan (TZS) treatment on (A,B) collagen I/III immunofluorescence; (C) ethidium bromide fluorescence and (D) mRNA levels of the NAD(P)H-oxidase subunit Nox-1, 22 $^{\text {phox }}$, and p47 $7^{\text {phox }}$ in mesenteric resistance arteries from 10 rats. ADV, adventitial layer; END, endothelial layer; MED, media layer; IEL, internal elastic lamina. Image size, $238 \mu \mathrm{m} \times 238 \mu \mathrm{m}$. Data are the mean \pm SEM of $n=6-8 .{ }^{* *} P<0.01$; ${ }^{*}{ }^{*} P<0.001 \mathrm{SO}$ vs. $1 \mathrm{O}$ and ${ }^{++} P<0.01 ;{ }^{+++} P<0.001 \mathrm{IO}$ vs. $1 \mathrm{O}+\mathrm{TZS}$ by one-way ANOVA followed by Tuckey test.
Autònoma de Barcelona. The authors are grateful to Dr. M. Iglarz from Actelion Pharmaceuticals Ltd., Switzerland, for the generous donation of tezosentan, and to our English language editor, Elaine Lilly, Ph.D.

\section{REFERENCES}

Amiri, F., Virdis, A., Neves, M. F., Iglarz, M., Seidah, N. G., Touyz, R. M., Reudelhuber, T. L., and Schiffrin, E. L. (2004). Endothelium-restricted overexpression of human endothelin-1 causes vascular remodeling and endothelial dysfunction. Circulation 110, 2233-2240.

Ballabeni, V., Barocelli, E., Bertoni, S., and Impicciatore, M. (2002). Alterations of intestinal motor responsiveness in a model of mild mesenteric ischemia/reperfusion in rats. Life Sci. 71, 2025-2035.

Baumbach, G. L., Didion, S. P., and Faraci, F. M. (2006). Hypertrophy of cerebral arterioles in mice deficient in expression of the gene for CuZn superoxide dismutase. Stroke 37, 1850-1855.

Baumbach, G. L., and Heistad, D. D. (1989). Remodeling of cerebral arterioles in chronic hypertension. Hypertension 13, 968-972.
Blomfield, J., and Farrar, J. F. (1969). The fluorescent properties of maturing arterial elastin. Cardiovasc. Res. 3, 161-170.

Boumaza, S., Arribas, S. M., OsbornePellegrin, M., McGrath, J. C., Laurent, S., Lacolley, P., and Challande, P. (2001). Fenestrations of the carotid internal elastic lamina and structural adaptation in stroke-prone spontaneously hypertensive rats. Hypertension 37, 1101-1107.

Briones, A. M., Arribas, S. M., and Salaices, M. (2010). Role of extracellular matrix in vascular remodeling of hypertension. Curr. Opin. Nephrol. Hypertens. 19, 187-194.

Briones, A. M., González, J. M., Somoza, B., Giraldo, J., Daly, C. J., Vila, E., González, M. C., McGrath, J. C., and Arribas, S. M. (2003). Role of elastin in spontaneously hypertensive rat small mesenteric artery remodelling. J. Physiol. 552, 185-195.

Carden, D. L., and Granger, D. N. (2000). Pathophysiology of ischemia-reperfusion injury. $J$. Pathol. 190, 255-266.

Cipolla, M. J., McCall, A. L., Lessov, N., and Porter, J. M. (1997). Reperfusion decreases myogenic reactivity and alters middle cerebral artery function after focal cerebral ischemia in rats. Stroke 28, 176-180.

Cuzzocrea, S., Chatterjee, P., Mazzon, E. Dugo, L., De Sarro, A., Van de Loo, F. A., Caputi, A. P., and Thiemermann, C. (2002). Role of induced nitric oxide in the initiation of the inflammatory response after postischemic injury. Shock 18, 169-176.

Daou, G. B., and Srivastava, A. K. (2004). Reactive oxygen species mediate endothelin-1-induced activation of ERK1/2, PKB, and Pyk2 signaling, as well as protein synthesis, in vascular smooth muscle cells. Free Radic. Biol. Med. 37, 208-215.

Duprez, D. A., and Cohn, J. N. (2007). Arterial stiffness as a risk factor for coronary atherosclerosis. Curr. Atheroscler. Rep. 9, 139-144.
Gourdin, M. J., Bree, B., and De Kock, M. (2009). The impact of ischaemia-reperfusion on the blood vessel. Eur. J. Anaesthesiol. 26, 537-547.

Harris, A. K., Hutchinson, J. R., Sachidanandam, K., Johnson, M. H., Dorrance, A. M., Stepp, D. W., Fagan, S. C., and Ergul, A. (2005). Type 2 diabetes causes remodeling of cerebrovasculature via differential regulation of matrix metalloproteinases and collagen synthesis: role of endothelin-1. Diabetes 54, 2638-2644.

Hayward, R., and Lefer, A. M. (1998). Time course of endothelial neutrophil interaction in splanchnic artery ischemia reperfusion. Am. J. Physiol. 275, 2080.

Intengan, H. D., Deng, L. Y., Li, J. S., and Schiffrin, E. L. (1999). Mechanics and composition of human subcutaneous resistance arteries in essential hypertension. Hypertension 33, 569-574. 
Intengan, H. D., and Schiffrin, E. L. (2001). Vascular remodeling in hypertension: roles of apoptosis, inflammation, and fibrosis. Hypertension 38, 581-587.

Jiménez-Altayó, F., Briones, A. M., Giraldo, J., Planas, A. M., Salaices, M., and Vila, E. (2006). Increased superoxide anion production by IL-1 $\beta$ impairs nitric oxide mediated relaxation in resistance arteries. J. Pharmacol. Exp. Ther. 316, 42-52.

Jiménez-Altayó, F., Caracuel, L., Pérez-Asensio, F. J., MartínezRevelles, S., Messeguer, A., Planas, A. M., and Vila, E. (2009). Participation of oxidative stress on rat middle cerebral artery changes induced by focal cerebral ischemia: beneficial effects of 3,4-dihydro-6-hydroxy-7-methoxy2,2-dimethyl-1(2H)-benzopyran (CR-6). J. Pharmacol. Exp. Ther. 331, 429-436.

Jiménez-Altayó, F., Martín, A., Rojas, S., Justicia, C., Briones, A. M., Giraldo, J., Planas, A. M., and Vila, E. (2007). Transient middle cerebral artery occlusion causes different structural, mechanical, and myogenic alterations in normotensive and hypertensive rats. Am. J. Physiol. Heart Circ. Physiol. 293, H628H635.

Khanna, A., Rossman, J. E., Fung, H. L., and Caty, M. G. (2001). Intestinal and hemodynamic impairment following mesenteric ischemia/reperfusion. J. Surg. Res. 99, 114-119.

Khavandi, K., Greenstein, A. S., Sonoyama, K., Withers, S., Price, A., Malik, R. A., and Heagerty, A. M. (2009). Myogenic tone and small artery remodelling: insight into diabetic nephropathy. Nephrol. Dial. Transplant. 24, 361-369.

Laurent, S., Boutouyrie, P., Asmar, R., Gautier, I., Laloux, B., Guize, L., Ducimetiere, P., and Benetos, A. (2001). Aortic stiffness is an independent predictor of all-cause and cardiovascular mortality in hypertensive patients. Hypertension 37, 1236-1241.

Li, L., Fink, G. D., Watts, S. W., Carrie, A., Northcott, M. S., Galligan, J. J., Pagano, P. J., and Chen, A. F. (2003). Endothelin-1 increases vascular superoxide via endothelin(A)NADPH oxidase pathway in lowrenin hypertension. Circulation 107, 1053-1058.
Lugowska-Umer, H., Umer, A., Sein-Anand, J., SokolowskaWojdylo, M., Wlodarkiewicz, A., and Korolkiewicz, R. P. (2008). Endothelin receptor blockers protect against ischemia/reperfusion impairment of gastrointestinal motility in rats. Pharmacol. Res. 57, 413-418.

Martens, F. M., Demeilliers, B., Girardot, D., Daigle, C., Dao, H. H., deBlois, D., and Moreau, P. (2002). Vesselspecific stimulation of protein synthesis by nitric oxide synthase inhibition: role of extracellular signalregulated kinases $1 / 2$. Hypertension $39,16-21$.

Martinez-Lemus, L. A., Hill, M. A., and Meininger, G. A. (2009). The plastic nature of the vascular wall: a continuum of remodeling events contributing to control of arteriolar diameter and structure. Physiology (Bethesda) 24, 45-57.

Martínez-Revelles, S., Caracuel, L., Márquez-Martín, A., Dantas, A. P., Oliver, E., D'Ocon, P., and Vila, E. (2011). Increased endothelin-1 vasoconstriction in mesenteric resistance arteries after superior mesenteric ischemiareperfusion. $\mathrm{Br}$. J. Pharmacol. doi:10.1111/j.1476-5381.2011.01617

Martinez-Revelles, S., Jiménez-Altayó, F., Caracuel, L., Pérez-Asensio, F. J., Planas, A. M., and Vila, E. (2008). Endothelial dysfunction in rat mesenteric resistance artery after transient middle cerebral artery occlusion. J. Pharmacol. Exp. Ther. 325, 363-369.

Masaki, T. (2004). Historical review: endothelin. Trends Pharmacol. Sci. 25, 219-224.

Massberg, S., and Messmer, K. (1998). The nature of ischemia/reperfusion injury. Transplant. Proc. 30, 4217-4223.

Mitsuoka, H., Unno, N., Sakurai, T., Kaneko, H., Suzuki, S., Konno, H., Terakawa, S., and Nakamura, S. (1999). Pathophysiological role of endothelins in pulmonary microcirculatory disorders due to intestinal ischemia and reperfusion. J. Surg. Res. 87, 143-151.

Mulvany, M. J., and Aalkjaer, C. (1990). Structure and function of small arteries. Physiol. Rev. 70, 921-961.

Murata, K., Motayama, T., and Kotake, C. (1986). Collagen types in various layers of the human aorta and their changes with the atherosclerotic process. Atherosclerosis 60, 251-262.
Novensa, L., Selent, J., Pastor, M., Sandberg, K., Heras, M., and Dantas, A. P. (2010). Equine estrogens impair nitric oxide production and endothelial nitric oxide synthase transcription in human endothelial cells compared with the natural 17 beta\}-estradiol. Hypertension 56, 405-411.

Ridley, N., and Green, S. E. (2001) Mesenteric arterial thrombosis diagnosed on CT. AJR Am. J. Roentgenol. 176, 549.

Romero, M., Jiménez, R., Sánchez, M., López-Sepúlveda, R., Zarzuelo, M. J., O’Valle, F., Zarzuelo, A., Pérez-Vizcaíno, F., and Duarte, J. (2009). Quercetin inhibits vascular superoxide production induced by endothelin-1: role of NADPH oxidase, uncoupled eNOS and PKC. Atherosclerosis 202, 58-67.

Sachidanandam, K., Hutchinson, J. R., Elgebaly, M. M., Mezzetti, E. M., Dorrance, A. M., Motamed, K., and Ergul, A. (2009). Glycemic control prevents microvascular remodeling and increased tone in type 2 diabetes: link to endothelin-1. Am. J. Physiol. Regul. Integr. Comp. Physiol. 296, G952-G959.

Sharifi, A. M., Li, J. S., Endemann, D., and Schiffrin, E. L. (1998) Effects of enalapril and amlodipine on small-artery structure and composition, and on endothelial dysfunction in spontaneously hypertensive rats. J. Hypertens. 16, 457-466.

Sise, M. J. (2010). Mesenteric ischemia: the whole spectrum. Scand. J. Surg. 99, 106-110.

Sonoyama, K., Greenstein, A., Price, A., Khavandi, K., and Heagerty, T. (2007). Vascular remodeling: implications for small artery function and target organ damage. Ther. Adv. Cardiovasc. Dis. 1, 129-137.

Stefanutti, G., Vejchapipat, P., Williams, S. R., Pierro, A., and Eaton, S. (2004). Heart energy metabolism after intestinal ischaemia and reperfusion. J. Pediatr. Surg. 39, 179-183.

Stenmark, K. R., Fagan, K. A., and Frid, M. G. (2006). Hypoxia-induced pulmonary vascular remodeling: cellular and molecular mechanisms. Circ. Res. 99, 675-691.

Takimoto, E., and Kass, D. A. (2007). Role of oxidative stress in cardiac hypertrophy and remodeling. Hypertension 49, 241-248.
Van den Akker, J., Schoorl, M. J., Bakker, E. N., and Vanbavel, E. (2010). Small artery remodeling: current concepts and questions. J. Vasc. Res. 47, 183-202.

Van der Hoven, B., Nabuurs, M., van Leengoed, L. A., Groeneveld, A. B. and Thijs, L. G. (2001). Gut luminal endotoxin reduces ischemiareperfusion injury of the small gut in germ-free pigs. Shock 16, 28-32.

Vila, E., and Salaices, M. (2005). Cytokines and vascular reactivity in resistance arteries. Am. J. Physiol. Heart Circ. Physiol. 288, H1016H1021.

Wong, L. C., and Langille, B. L. (1996). Developmental remodeling of the internal elastic lamina of rabbit arteries: effect of blood flow. Circ. Res. 78, 799-805.

Xu, F. P., Chen, M. S., Wang, Y. Z., Yi, Q. Lin, S. B., Chen, A. F., and Luo, J. D. (2004). Leptin induces hypertrophy via endothelin-1-reactive oxygen species pathway in cultured neonatal rat cardiomyocytes. Circulation 110 , 1269-1275.

Zhang, W., Zhu, W., Zhang, J., Li, N., and Li, J. (2008). Protective effects of glucagon-like peptide 2 on intestinal ischemia-reperfusion rats. Microsurgery 28, 285-290.

Conflict of Interest Statement: The authors declare that the research was conducted in the absence of any commercial or financial relationships that could be construed as a potential conflict of interest.

Received: 15 April 2011; accepted: 15 December 2011; published online: 05 January 2012.

Citation: Caracuel L, Jiménez-Altayó F, Romo M, Márquez-Martín A, Dantas AP and Vila E (2012) Transient mesenteric ischemia leads to remodeling of rat mesenteric resistance arteries. Front. Physio. 2:118. doi: 10.3389/fphys.2011.00118

This article was submitted to Frontiers in Vascular Physiology, a specialty of Frontiers in Physiology.

Copyright (C) 2012 Caracuel, JiménezAltayó, Romo, Márquez-Martín, Dantas and Vila. This is an open-access article distributed under the terms of the Creative Commons Attribution Non Commercial License, which permits noncommercial use, distribution, and reproduction in other forums, provided the original authors and source are credited. 